\title{
WHEN OTHERS \\ PASSING BY BEHOLD: \\ MEDIA STUDIES AND \\ ARCHIVES ACROSS \\ CULTURES \\ MATT COHEN
}

MATT COHEN is a professor in the Department of English at the University of Nebraska-Lincoln and a Faculty Fellow at the Center for Digital Research in the Humanities there. He is the author or editor of five books, including The Networked Wilderness: Communicating in Early New England (University of Minnesota Press, 2010) and, most recently, Whitman's Drift: Imagining Literary Distribution (University of Iowa Press, 2017). He is a contributing editor at the Walt Whitman Archive (http://www.whitmanarchive.org) and a co-editor of the Charles Chesnutt Digital Archive (https://chesnuttarchive.org/). Cohen is currently at work on a new book on intercultural theory and method in early American studies, tentatively titled The Silence of the Miskito Prince: Imagining Across Cultures in Early America. 
In the month of May, in 1633 , the Wampanoag people in the area near now-famous Plymouth Plantation made a prediction, duly recorded by William Bradford:

[A]ll the month of May, [there] was such a quantity of a great sorte of flies, like (for bigness) to wasps, or bumble-bees, which came out of holes in the ground, and replenished all the woods, and ate the green-things, and made such a constant yelling noise, as made all the woods ring of them, and ready to deafen the hearers. They have not by the English been heard or seen before or since. But the Indians told them that sickness would follow, and so it did in June, July, August, and the chief heat of summer. ${ }^{\text {. }}$

Bradford's Of Plymouth Plantation tells us enough to guess that these 'flies' were of the species magicicada septendecim, or seventeen-year cicadas. The insects make several kinds of calls, one of which sounds like yelling, especially when there are a lot of them. This was before much of eastern Massachusetts got paved, so the chorus was likely astonishing, especially to the uninitiated, as Bradford confesses his fellow religious emigrés to be.

Many readers today might see in this event and its recording a dark ecological warning: The ignorance about the powers of the earth of the newly arrived developers of America; English wonderment at indigenous knowledge even as Of Plymouth Plantation records the violent displacement of Native people; and the deadliness of the "chief heat of summer." It's a romantic vision, but for all that, perhaps a salutary one. But if for the Wampanoags the cicadas were spiritual heralds, the swarm was also an epidemiological and historical marker. The holes they made upon emerging formed a predictive pattern, delineated a submerged archive. The last time those cicadas had appeared, after all, must have been during the massive epidemics suffered by the Natives on the eve of English settlement, in I6I6-I7-though Bradford seems not to have inquired far enough to discover that connection. The patient waiting of the cicadas as they grew and their seeming re-birth after such a length of time, no less than the terrors they induced in the English, may point to other, less romantic, symbolisms in the long view-perhaps to what N. Scott Momaday has called the Native community's "long outwaiting" of colonial settlement. ${ }^{2}$

Bradford's inclusion of the detail about the cicadas coming out of "holes in the ground," and his narrative's tendency to cordon off or obscure indigenous archival knowledge, start us on a trail of links and resonances that knit together media, history, culture, and how we study

I William Bradford, History of Plymouth Plantation, I606-I646, William T. Davis, ed. (New York: Charles Scribner's Sons, 1908), 514.

2 N. Scott Momaday, House Made of Dawn (New York: Harper Perennial Modern Classics, 2010), 53 . 
all of these things. The tension between how American Indian communities built or apprehended archives and the construction of Bradford's account cues this essay's contemplation about how we might build digital archives today. My focus is less on media, per se, than on the movement from media to archive as it has been conditioned by colonialism. Even so precise an observer of the world as James Gibson, in I986 and amidst a self-reflexive revolution in anthropological method, could reiterate the time-worn equation: "images, pictures, and writing, insofar as the substances shaped and the surfaces treated are permanent, permit the storage of information and the accumulation of information in storehouses, in short, civilization." ${ }^{3}$ No permanent information storage, no civilization.

For centuries, indigenous American media worlds and their confrontation with European systems and modes of communication have been an evidentiary site for debates about the role of media technologies, formats, and protocols in human history and consciousness. ${ }^{4}$ Here I continue that conversation but leave behind some of the concerns and assumptions that have most clearly made the debate itself a sometimes unwitting partner in colonization. Instead I emphasize what I would claim as the conjunctive intercultural importance of the forms that archives take, offering a methodological reflection on the architecture, broadly understood, of digital cultural archives today. I focus on early colonial American media contests - and how Native American archival practices have been contained by subsequent representations of them - to highlight the Western liberal practices and desires that subtly shape the building, maintenance, and promotion of electronic archives today. Disagreements today about networked archives are often continuations of contests over information design and access with colonial origins and objectives. But such disagreements are also opportunities to change the way archives function, both in the imagination and in the legal architectures of states, tribes, and other collectives, by considering forces beyond any of those architectural epistemes as we build the digital archives that will represent the things of the North American past for the future.

3 James J. Gibson, The Ecological Approach to Visual Perception (Hillsdale, New Jersey: Lawrence Erlbaum Associates, I986), in (emphasis added).

4 See Jorge Cañizares-Esguerra, How to Write the History of the New World: Histories, Epistemologies, and Identities in the Eighteenth-Century Atlantic World (Stanford: Stanford University Press, 2002); José Rabasa, Writing Violence on the Northern Frontier: The Historiography of Sixteenth-Century New Mexico and Florida and the Legacy of Conquest (Durham, NC: Duke University Press, 200o); Michel de Certeau, Heterologies: Discourse on the Other trans. B. Massumi (Minneapolis: University of Minnesota Press, I986); Jacques Derrida, Of Grammatology, trans. G. C. Spivak (Baltimore: Johns Hopkins University Press, 1976). 


\section{INSCRIPTION AND HISTORICISM}

D. F. McKenzie suggested in the I980s in his study of the Treaty of Waitangi with the Maori in New Zealand, and scholars like Walter Mignolo and José Rabasa have argued in the context of Spanish colonialism, that close study of the materiality and genres of indigenous media reveals a less utopian story than the triumphalist myth of alphabetic literacy leading to human freedom would claim. The same goes for how we archive and give access to media of the past.

Consider the criticism embodied in the National Museum of the American Indian's Bibles and guns exhibit. The exhibit, designed in part by Comanche cultural critic and art historian Paul Chaat Smith, displays over one hundred Bibles translated into American Indian languages on one side of a curved display wall, and a swarm of guns, all pointing the same direction, representing the evolution of firearms used both by and against Natives on the other side. Though it's quieter than Bradford's cicada invasion, the visual-spatial effect is similar. The installation is located on the top floor of the museum, a use of the space that enhances the sense of being channelled and constrained that is instilled by the gallery's winding layout. ${ }^{5}$ If the Bible functions metonymically for the mediums of writing and the book, the display counterposes two different technologies that, from one perspective, might be regarded as at odds. But then, it suggests to the contrary, these two kinds of objects have worked towards the same ends. One more turn of the screw: The exhibit's signage stresses the way in which these technologies were also adapted and mastered by American Indians. ${ }^{6}$ For media scholars, such a display in a museum on the National Mall of the United States, with its national rhetoric of equality and democratic access to education, might provoke a series of questions, from the historical to the affective: At what cost have books, in this case, moved across the boundaries of race-and a racialism which rose coevally with, and perhaps out of, colonial expansion? Are indigenous media now, as has been the case for some Native communities in the past, in certain cases designed expressly not to cross boundaries, to remain off the grid? If the social practices, rules and manners associated with media are as important as the medium, as many critics argue, do media in fact ever really 'cross' cultures? The display seems designed in part to make a settler colonial museum visitor feel the constraints of colonialism's media culture in the

5 This display, curated by Jolene Rickard, Ann McMullen, and Paul Chaat Smith, was part of the exhibition Our Peoples: Giving Voice to Our Histories, National Museum of the American Indian, Smithsonian Institution, Washington, D.C.

6 For discussions of this and other aspects of the NMAI, see Amy Lonetree and Amanda J. Cobb, ed., The National Museum of the American Indian: Critical Conversations (Lincoln: University of Nebraska Press, 2008). 
way an American Indian might. A largely Native-designed museum, the NMAI in this exhibit and in others puts visitors' senses of media, authority, and history into uncomfortable relations, beholding the archive even as they are held by it.

Thinking about media and early American colonization throws into relief the way a phrase like 'new media' implicitly positions itself as transcending cultural differences, even as it paradoxically obscures the historical meanings attached to media development under colonization. ${ }^{7}$ To Natives at first contact, alphabetic writing and print were new media; books, pamphlets, broadsides, and the like were new formats. Controversies among indigenous intellectuals, politicians, and artists from early encounter times to today have kept a focus on the politics of entanglement these media and formats offer. An early colonial narrative claim - that Indians regarded these technologies as gifts from the gods - was important to some Europeans in justifying dispossession and enslavement. But the incomplete qualities of that claim were clear to any colonizer confronting indigenous rebellion or, more importantly, the rapid pace at which indigenous people began to use such forms and formats. Europeans debated with themselves which American forms and formats were new, but the generally agreed-upon story has been that championing print and alphabetic literacy was key to a colonial ideology based on the linked concepts of civilization, progress, and Christianity. ${ }^{8}$ No one doubted that indigenous people possessed information media and formats, both familiar, such as painting, architecture, pottery, and spoken language, and less familiar, such as knotted strings, tattooing, and piles of sticks. But the rhetoric of superiority, as Eric Wolf has argued, was built around the question of whether or not these could these be archived - could history be made and transmitted beyond memory? ${ }^{9}$

The relationship between media and historicism is an important hinge in the articulation of a concept of 'media' to the colonialist legacy that shapes discourses of technology and media today (and does so strikingly in the United States). The outlines of that relationship are visible in Thomas Harriot's I 588 account of Virginia and an observation by the Pilgrim Edward Winslow forty years later in New England. A Briefe and True Relation of the New Found Land of Virginia became one of the most

7 See Lisa Gitelman, Always Already New: Media, History, and the Data of Culture (Cambridge: MIT University Press, 2006); and Brian Hochman, Savage Preservation: The Ethnographic Origins of Modern Media Technology (Minneapolis: University of Minnesota Press, 2014).

8 See Phillip Round, Removable Type: Histories of the Book in Indian Country, I663-I88o (Chapel Hill: University of North Carolina Press, 2010); Hilary Wyss, Writing Indians: Literacy, Christianity, and Native Community in Early America (Amherst: University of Massachusetts Press, 200o); Matt Cohen and Jeffrey Glover, eds., Colonial Mediascapes: Sensory Worlds of the Early Americas (Lincoln: University of Nebraska Press, 2014).

9 See Eric Wolf, Europe and the People Without History (Berkeley: University of California Press, 1982). 
popular accounts of America, and, with the other twelve volumes in a series called America, one of the most enduring sources for what today we would call ethnographic information about American Indians. Harriot, a mathematician who recorded an account of the 1585 journey to Virginia backed by Sir Walter Raleigh, offered this description of Native reactions to English technologies:

Most thinges they sawe with us, as Mathematicall instruments, sea compassess ...gunnes, bookes, writing and reading ...and manie other thinges that wee had, were so straunge unto them, and so farre exceeded their capacities to comprehend the reason and meanes how they should be made and done, that they thought they were rather the works of gods then of men, or at the leastwise they had bin giuen and taught us of the gods. ${ }^{\text {IO }}$

Harriot's account, together with a set of engravings by Theodor de Bry based on watercolour sketches John White made on-site, make clear that the Virginians not only have inscriptive technologies such as the tattoo, but use them as an integral part of social organization (fig. I). As the caption to "The Marckes of sundrye of the Cheif mene of Virginia" reads, "The inhabitats of all the cuntrie for the most parte haue marks rased on their backs, wherby yt may be knowen what Princes subiects they bee, or of what place they haue their originall."

FIG I

Theodor de Bry, "The Marckes of sundrye of the Cheif mene of Virginia," engraving from A Briefe and True Report (I590). John Carter Brown Library.

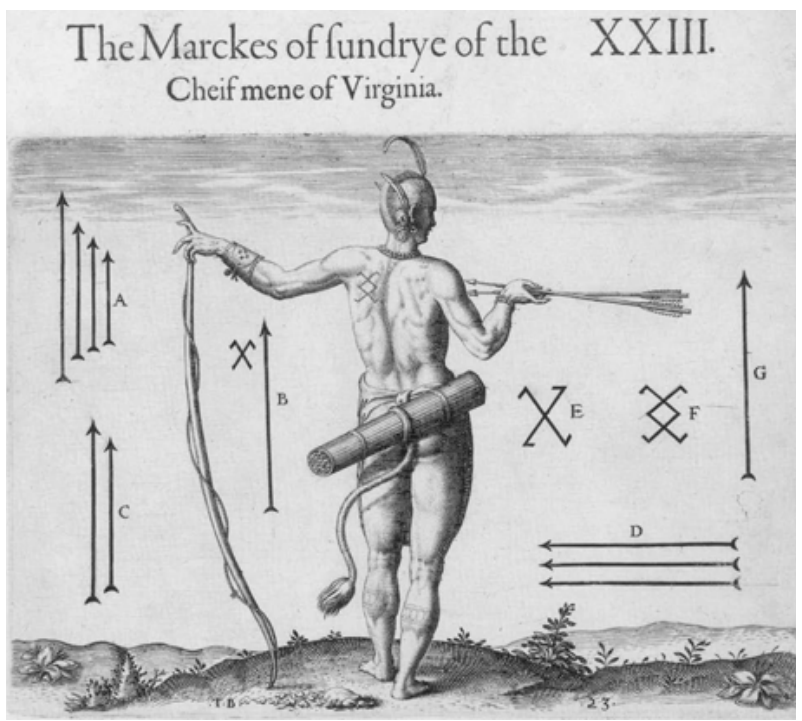
I590), 27 
Elsewhere in his account, Harriot likens the Virginians to the Picts, his English readers' ancestors; the parallel humanizes the Natives, even as it distances them by exemplifying the European ability to compare and to master history that inscription practises such as writing and engraving seem to enable by leveraging time and space. "When viewers of the Report gazed at its images of American Indians," Michael Gaudio has argued, "they were declaring their difference from the savage by doing precisely that which the savage cannot do-by achieving a perspective on the world." "I

The leaders of the Separatists who settled Plymouth colony, such as Bradford, had almost certainly read Harriot's account, along with many others available by that time. While events such as the I622 massacre by Powhatans of settlers in Virginia had tarnished the utility of the trope of writing as a gift of the gods, Bradford's account of the cicadas still attempts to position European knowledge as superior by exemplifying how collecting, storing, and narrating information in written form can improve a community. But it was not the only account.

The fact that it was almost certainly Wampanoags that told the Pilgrims about those "greate...flies" that emerged from holes in the ground reveals a perhaps not completely coincidental congruence: The Wampanoags were known to use holes in the ground to record human events. ${ }^{12}$ Bradford's fellow Pilgrim and negotiator Edward Winslow, one of the more sympathetic and attentive observers of indigenous ways, published a description of the holes and the protocols associated with them:

Instead of Records and Chronicles, they take this course, where any remarkable act is done, in memory of it, either in the place, or by some path-way near adjoining, they make a round hole in the ground about a foot deep, and as much over, which when others passing by behold, they enquire the cause and occasion of the same, which being once known, they are careful to acquaint all men, as occasion serveth therewith. And lest such holes should be filled, or grown up by any accident, as men pass by they will oft renew the same: By which means many things of great Antiquity are fresh in memory. So that as a man travelleth, if he can understand his guide, his journey will be the less tedious, by reason of the many historical Discourses will be related unto him. ${ }^{13}$

This passage revises, in a complex way, Harriot's claim that the Americans had "no letters nor other such meanes as we to keepe recordes of the (Minneapolis: University of Minnesota Press, 2008), xix.

12 See Neal Salisbury, Manitou and Providence: Indians, Europeans, and the Making of New England, 1500-I643 (New York: Oxford University Press, 1982).

13 Good News from New England by Edward Winslow: A Scholarly Edition, Kelly Wisecup, ed. (Amherst: University of Massachusetts Press, 2014), ir I. 
particularities of times past." ${ }^{\text {I4 }}$ It is significant that Winslow does not proceed by analogy. Rather than claim a relation-inferior, universal, or otherwise - to Western practices, his description breaks down the archiving of "historical discourses" into components: a material inscription, a method of transmission, a conservation strategy. Memory and social practice are regarded as key, just as in the interpretation of any kind of inscription, since the holes cannot interpret themselves.

The choice of location, 'in the place' or nearby, is also significant, as the interaction with archival information proceeds within the richly informative space of the event recorded. Information access is mostly, but not completely, open: A passer-by can request the information, which triggers a 'careful' reproduction of the information from the archive, but with the minor, significant qualification that the telling is 'as occasion serveth therewith' and only if you can understand your guide. The final protocol, of rounding out the hole after telling the story to keep it distinctive, blends pragmatism, a lesson about the decay that nature brings on all attempts at remembering, and a symbolic representation of the social nature of information - of the participatory potential of memorial institutions. Almost everyone is an archivist here; in the logic of this preservation system, to hear or to tell the 'many historical discourses' of the Algonquian forests is to take some responsibility for perpetuating them.

That Winslow, unlike Bradford or Harriot, foregrounded not just the media that eastern Algonquians used but also their protocols for storing and retrieving information about the past, suggests the complex differences among English reactions to the new transmissive technologies and formats they were witnessing and into which they were being folded. Negotiators like Winslow and his contemporary Roger Williams had to pay close attention to how Algonquians stored and retrieved information, even when they had a decent working grasp of the difficult grammar of Algonquian dialects. Winslow's account and Williams's A Key into the Language of America (i643) are among the most important sources today for ethnohistorical information about seventeenth-century indigenous information practises in the region. But the study of them is difficult, because their depictions of American Indians are framed by religious, commercial, political, and other influential concerns of their writers and the audiences for these texts. ${ }^{15}$

The difficulty of that movement between the accounts of the past and the ones that we offer today can hold true even, sometimes

See Patricia Rubertone, Grave Undertakings: An Archaeology of Roger Williams and the Narragansett Indians (Washington, DC: Smithsonian Institution Press, 20or); Matt Cohen, The Networked Wilderness: Communicating in Early New England (Minneapolis: University of Minnesota Press, 2010); Andrew Newman, On Records: Delaware Indians, Colonists, and the Media of History and Memory (Lincoln: University of Nebraska Press, 2012); Nicole Gray, 'Aurality in Print: Revisiting Roger Williams's A Key into the Language of America', PMLA izI.2 (2016): 64-83. 
especially, when careful attention is being paid to the material histories of inscription practises. A recent scholarly analysis of the importance of media history in analysing the colonial past serves as a cautionary example. In Engraving the Savage, Michael Gaudio points to the fundamental importance of the techniques of engraving in creating the Western idea of the 'savage'. Alongside and in conjunction with the art of printing, copperplate engraving exemplified technological progress even as it represented people who supposedly could not imagine it, creating the fulcrum of the savage-civilized distinction. Gaudio points to the multivalent presence of a copper plate, uninscribed, around the neck of one of De Bry's chiefs, in an engraving in Harriot's Report. The image of the neck plate is a nexus, where the savage within and the potential of the savage to become civilized rotate around an axis of both authenticity (this is an engraving of an Indian, who is therefore real) and fantasy (this is an engraving, which Indians can't make-or can they?).

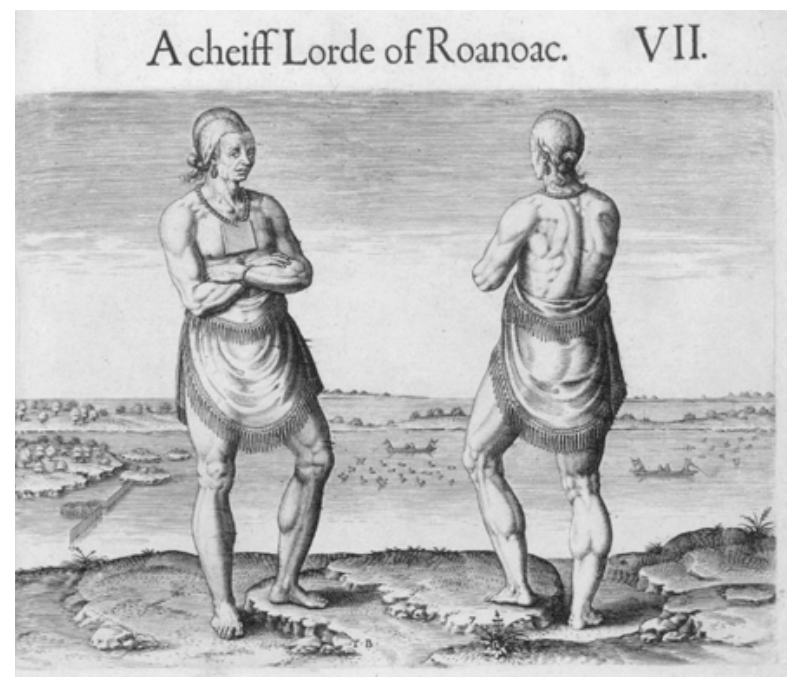

Gaudio stops short of articulating the real implication of his argument. The copper plate that Harriot describes as indicating the chief's 'authority' is a reminder that you don't have to engrave an object yourself in order to use it to create authority: "engraving," Gaudio says, "begins to look a lot like the matter with which the savage signifies his own authority." ${ }^{16}$ This is to say, by extension, that 'civilisation' is a function of a capacity for representation, rather than the acquisition of particular
FIG 2

Theodor de Bry, "A cheiff Lorde of Roanoac," engraving from Harriot, A Briefe and True Report (I590). John Carter Brown Library. 
skills or tools. Knowing that the meaning of 'civilization' was undermined by the very technologies that represented it helps us understand, in part, why that unstable culture was so effective at convincing itself to dominate American indigenous people. But, in the end, it does not move us past that paradigm of domination, because the scholarly act does not enfold an awareness of, nor does it enact, alternative representational epistemes. Whether the chief's other markings constitute an engraving technology, or the blank plate signifies a future potential for it (and I think both of those readings were certainly available and likely), the risk of putting illustration and engraving at the evidentiary heart of our analytics is that these might impede us from perceiving other ways that humans have organized and recorded their worlds. The intense scholarly interest in, almost fetishization (perhaps required by the historical-scientific method) of the materiality of inscription practices sits in uneasy relationship to the awareness that engraving, in this case, has in the big picture been a blinding act that has had violent effects on real people. To understand European technologies in this case is to do so using a logic derived from Western philosophy and the technologies that propagated it. Gaudio rightly observes that too often, "the material body of the signifying mark becomes a secondary or accidental quality subordinated to its emblematic value." ${ }^{17}$ But if the tendency of previous analyses of images of the New World has been to look too quickly past the medium to the signs (with a few notable exceptions), the tendency of textual studies and art history hasn't often been to collaborate with indigenous people or consider colonial media technologies in the same frame as on-the-ground slavery, murder, and dispossession. ${ }^{18}$

The electronic archive seems to offer an occasion for just such collaboration and reconsideration. Yet I think that the digital archive, considered as an illustrative technique, carries the same risks that engraving brought with it. What we find in an electronic archive-surrogates of texts, objects, and images, and metadata about them - tends to be presented in a unifying visual frame, removed from the sociality and the three-dimensional space of the brick-and-mortar archive. Derrida would remind us that the sociality of the archive, who gets in and who does not, who can visit and who cannot, who is funded and resident and who is not, and so on, constitute the same kind of authority as engraving as well. ${ }^{19}$ But this is something we tend to believe doesn't happen through Their Literature (New York: Cambridge University Press, I992); and Walter
Mignolo, The Darker Side of the Renaissance: Literacy, Territoriality, and Colonization (Ann Arbor, MI: University of Michigan Press, 1995).

I9 See Jacques Derrida, Archive Fever: A Freudian Impression, trans. E. Prenowitz (Chicago: University of Chicago Press, 1996). 
with electronic archives if they are publicly available. In other words, archive-builders, even if they are not on a civilizing mission, when they represent indigenous materials are entangled in the same history of power and of ideas of cultural difference that the European engravers of Native peoples in the sixteenth century were.

\section{OTHERS, PASSING BY}

New media in the early English New World functioned at the cutting edge of colonial exploitation and expropriation. The archives that were created over the course of the colonial expansion of North America were media records, to be sure, but they were also tools of colonial mastery. This is equally true of the compendium of letters, political documents, and historical narrative that make up Bradford's Of Plymouth Plantation and of the collections and publications of historical societies like the American Antiquarian Society, which was founded in I8I2 at a moment when the Puritan and Native American past were being claimed as the basis of the United States' exceptionalism. ${ }^{20}$ What lessons, then, does the colonial era hold for us today, given that our access to it is profoundly conditioned by the histories of these institutions and narratives? Should we not open and simplify the protocols, both for accessing and for including objects within the archives, and transcend the colonial dynamics of selection, historicization, and dispossession that characterized the information management regimes of the past?

If what Lisa Lowe calls the "intimacies of four continents" are to be uncovered by research that looks beyond ethnic or national boundaries and links hitherto obscured archives together, then the networked electronic infosphere would seem to offer quick passage to the revelation of North America's enmeshed histories. ${ }^{2 \mathrm{I}}$ In early American studies, in particular, the study of indigenous materials has been aided by the World Wide Web's multimedia capacities both in content and to the degree that they transform users' expectations of how media interrelate to create meaning. "Semiotic functions," writes Galen Brokaw of indigenous media, "are distributed across a number of different media, most, if not all, of which also employ to one degree or another multiple types of semiotic conventions." ${ }^{22}$ While Brokaw argues that this is true in any culture, a particular attention to other-than-textual and interdependent modes of communication has taken hold in early American studies as a way of analysing encounter and colonization that moves across both

20 See Abram Van Engen, The Meaning of America: How the United States Became the City on a Hill (New Haven, CT: Yale University Press, forthcoming).

2I Lisa Lowe, The Intimacies of Four Continents (Durham: Duke University Press, 2015).

22 Galen Brokaw, 'Indigenous American Polygraphy and the Dialogic Model of Media'. Ethnohistory 57.I (Winter 2010), 220. 
the European-indigenous divide and contemporary disciplinary ones. ${ }^{23}$ Being able to collocate a range of different media in an online space has certainly made this argument more forceful, and promises important revelations that will alter the field in profound ways. But these capabilities have not yet revolutionized the teaching of early America in a widespread way. The utopian language of freedom and interconnection that often permeates discussions of new media and digitization has been well critiqued. But even the now equally familiar indictments of the shallowness of humanities big data analysis or the corporatizing complicity of neoliberal digital humanism take a form that envisions technology creating, if not a unified society, one with deeper and better shared meaningfulness and ethos. Even if this isn't an individualistic stance, it is still a Western one, not particularly focused on the sacred and implicitly governed by a progressivist historical sensibility. Knowing that an enormous computational and infrastructural effort is required to make Internet-based computer work appear fluid and democratic, and that such an appearance can be exploited by sinister forces both major and minor, leaves us with the question of what might be beyond the narrative of progress and its dependence upon the concept of openness. ${ }^{24}$

It seems as if Western openness, in the cases of blogs, Facebook, and Twitter, for example, is both aiding liberation worldwide and cultivating disastrous new forms of fascism. This lesson about technology, and the fondest wishes for it to concretize progress, is learned time and again; the unveiling of its double-edgedness has become a familiar ritual. The network giveth, and the network taketh away. Geolocation technologies offer a good example. Once I worked with a group of computational linguists on a project to improve the machine recognition of place names in text-based sources. I wanted, when teaching an early travel narrative, to generate a map of all of the toponyms in it quickly and reliably — but place names are notoriously difficult to disambiguate. My part of the project used literary texts to test our algorithms, while another group used the Twitter feed. They were perfecting an algorithm

See also Hilary Wyss and Kristina Bross, eds., Early Native Literacies in New England: A Documentary and Critical Anthology (Amherst: University of Massachusetts Press, 2008); Sandra Gustafson, Eloquence Is Power: Oratory and Performance in Early America (Chapel Hill, NC: University of North Carolina Press, 20oo); Susan Stabile, Memory's Daughters: The Material Culture of Remembrance in Eighteenth-Century America (Ithaca, NY: Cornell University Press, 2004); and Robert Blair St. George, Conversing by Signs: Becoming Colonial in Early America (Ithaca, NY: Cornell University Press, 2000).

24 See Mark Poster, What's the Matter with the Internet? (Minneapolis: University of Minnesota Press, 200I); Matthew Kirschenbaum, Mechanisms: New Media and the Forensic Imagination (Cambridge, MA: MIT Press, 2008); and most recently see Daniel Allington, Sarah Brouillette, David Golumbia, 'Neoliberal Tools (and Archives): A Political History of Digital Humanities', Los Angeles Review of Books (I May 2016) $<$ https://lareviewofbooks.org/article/neoliberal-tools-archives-political-history-digital-humanities/\#! > and the subsequent controversy over it. 
that guesses the location of a given tweet based on comparing its content to the overall feed and other contemporary textual sources. ${ }^{25}$ Using Twitter feeds to locate people geographically, in addition to sounding cool, is an exciting test for computational linguistics and certainly helps us build better models for disambiguating toponyms in other textual sources. It is not difficult, however, to imagine how such an ability might be exploited in order to do violence. The frontier always moves, and it doesn't always move forward.

Let us return to Winslow's memory hole and dig it out a bit more, to think about digitally based Native archiving today. Western standards of preservation and access, from libraries to the online Open Access movement, seem self-evidently beneficial, and are often backed by a claim to promoting democracy. But the Wampanoag insistence on the dimensions of sociality, repetition, and the responsibility for curation held by each visitor to the archive implies different standards than the ones we tend to associate with digital archives. Indigenous communities' protocols for information access, while as elaborate as those of traditional Western archives (some places undergrads can look at manuscripts; some places you have to have a doctoral degree to do so, and so on), sometimes clash with the ideology of open or meritocratic access to information. A number of scholars, archivists, and librarians are working on the question of how to take up a more partial, but perhaps more ethical, approach to building archives online.

For many indigenous people, the stakes of controlling access to cultural information are high, even as the need to present a public face for purposes of achieving or maintaining sovereignty calls for a modicum of self-exposure. While the United States' Native American Graves Protection and Repatriation Act provides guidance for archivists in the physical realm, allowing for the return of mortal remains and artefacts to tribes from anthropological collections and other holdings, its domain is limited and the question of its applicability to the digital world is still open. Controlling access to information about cultural heritage is a problem that anthropologists of aboriginal Australia, among others, have been grappling with for years, using database technologies and interface design. Cultural anthropologist Kimberly Christen's projects are designed to privilege the cultural restrictions of information sharing in indigenous contexts. Her Mukurtu Wumpurrarni-kari Archive used Warumungu cultural protocols to restrict database access based on users' information: by family, gender, status in the tribal community, and country of origin. Within the archive, content is also organized with Geodesic Grids', Proceedings of the 49th Annual Meeting of the Association for Computational Linguistics, Portland, OR (June 19-24, 2011) 955-964. 
according to Warumungu cultural categories. The archive was created in an ongoing collaboration with Warumungu community members. ${ }^{26}$ The Mukurtu Archive takes advantages of operating systems' ability to set user-based permissions and the complex contingent relations among tables available in databases to create a digital model of the social structure of information access in an aboriginal community and, by extension, to present its values through transmissive activity. As in the case of Winslow's 'passer by', then, a casual visitor to the archive may not be able to hear or see much at all without a tribal member sharing. ${ }^{27}$

The principles that informed the architecture of the Mukurtu Archive were used by Christen's group to create a more general content management system, Mukurtu CMS. The platform has been used by a number of different groups and institutions, and facilitates not just community archiving and access control, but in some instances the collaboration of anthropologists, librarians and curators, and tribal members in cultural preservation efforts that bridge group boundaries - an approach Christen calls "reciprocal curation." ${ }^{28}$ But the success of the platform generally will be a function not just of its technological affordances and the broader sustainability of web-based cultural preservation. Not all tribes are federally recognized, which means that both policy domains and access to resources for cultural preservation can vary substantially. Like all groups, tribes are fluctuating entities, and their members' attitudes towards cultural heritage are heterogeneous, shifting, and contested. Any archivist enters ongoing internal debates when initiating a preservation project with a tribe, and tribal technologists are often pulled in multiple directions by competing community needs. All of these complexities take place within a landscape of archival possibility that is increasingly shaped by the presence of a small number of tribes with large reservation gaming incomes and, as a result, uncharacteristic latitude in how they can approach cultural archiving.

These complexities, together with the success of recent indigenous digital archive initiatives, raise questions that return us to the early colonial era and how we tell its stories, by way of broad problematics in the social lives of archives. What implications does the 'reciprocal curation' approach have beyond the indigenous context, for building cultural heritage archives? What constitutes a group, for the purposes

See the discussion of Mukurtu, other indigenous cultural heritage preservation sites, and the tradeoffs of leading content management platforms at http://www.mukurtuarchive.org/.

27 Kimberly Christen and Chris Cooney, 'Digital Dynamics across Cultures', Vectors Journal (2008) <http://www.vectorsjournal.org/projects/index.php?project=67\&thread=Proje ctCredits $>$. For another example of a digital archive-building project with decolonial potential, see the Colored Conventions project, http://coloredconventions.org.

28 Kimberly Christen, 'Opening Archives: Respectful Repatriation'. The American Archivist 74 (2011), 196. 
of pursuing this sort of database ethics? A tribe is a political entity (among other things), with boundaries (however controversial) and a specific colonial history in relation to a state government. But what about a religious group like the Amish in the United States? Or cases in which religious separatism and Native American history cross - should scholarly standards encourage editors of works like William Bradford's or Edward Winslow's to collaborate with indigenous communities? Cherokee scholar Betty Booth Donohue, in a monograph on Bradford and Of Plymouth Plantation, argues that Bradford's is an "Indian book," and one might extrapolate from this to argue that its curation, if curation is imagined as an act of cultural heritage-making, ought best to be made an inter-cultural collaborative activity. ${ }^{29}$

What rethinkings of archive-building will be required, if an emphasis on collaboration and mutual responsibility is to be foundational? The rise of 'post-custodial curation' has occasioned thinking among museums, libraries, and archives about the kinds of training and institutional resource allocation required to build — or un-build - archives across cultures in this way. For a number of years, the American Libraries Association debated a proposition about how libraries should handle 'Traditional Cultural Expressions' - a proposal that in its first draught form put pressure on libraries to maintain close ties with Native communities and to give them considerable control over access policies. ${ }^{30}$ If a version of this proposition passes and becomes a recommendation, it will mean major changes in the ways in which libraries relate to Native communities, and much more time and energy devoted to decisions about how or whether to offer access to library-held resources of indigenous materials. Curation models in which original objects stay with cultural groups, while umbrella organizations host them digitally, are beginning to spread as well: The Human Rights Documentation Initiative at the University of Texas at Austin uses this model, and in at least one African case even has mirrored web and local storage, providing a computer and database locally to a museum because of the unpredictability of local Internet access. ${ }^{3 \mathrm{I}}$

29 Betty Booth Donohue, William Bradford's Indian Book: Being the True Roote and Rise of American Letters As Revealed by the Native Text Embedded in Of Plimoth Plantation (Gainesville: University Press of Florida, 2011).

30 See for example the posts at the American Libraries Association web site on TCEs, including the 'TCE Task Force Final Report', <http://wo.ala.org/tce/201 I/or/28/tce-task-forcefinal-report/>. Librarians have also been actively involved in both the creation and the critique of various international standards and recommendations for handling Traditional Cultural Expressions, including the World Intellectual Property Organization's.

3I The Human Rights Documentation Initiative, University of Texas Libraries, < http:// www.lib.utexas.edu/hrdi/ $>$. See in particular the discussion of the politics and mechanics of 'digital return' in Hannah Alpert-Abrams, 'Unreadable Books: Early Colonial Mexican Documents in Circulation', PhD diss, University of Texas at Austin (2017). 
There are many web-based projects that emphasize how the history and structure of communities of interest might serve as the structural guide for archive building and interface design. Some operate in the academic domain, such as the Great Lakes Research Alliance for the Study of Aboriginal Arts and Cultures, a collective of indigenous researchers, archivists, and scholars, which uses "information technology to digitally reunite Great Lakes heritage that is currently scattered across museums and archives in North America and Europe with Aboriginal community knowledge, memory and perspectives." ${ }_{32}$ The He Pātaka Kupu Ture (Legal Māori Archive) focuses on legal matters between states and specific groups in New Zealand. He Pātaka Kupu Ture is explicit in restricting the documents it offers to those "designed to be circulated and read by many." 33 And, of course, indigenous people are, like almost everyone else, using the web to create collections, both in mass applications like Flickr and Facebook and in more specialised, explicitly pro-Native venues such as IsumaTV. IsumaTV, created by the Inuit makers of the Fast Runner film series, is a multimedia publication platform that allows for broadcast, user-generated content hosting, and interactivity, organized by channels. The interface, simple and clean, seems to convey a corporate feel, and its one-framework-fits-all logic - put your multimedia here - seems Google-inspired. Yet the site looks more like the Wampanoag hole as one digs deeper: It lays claim to, and argues, the common political and representational situation of all indigenous people. "Our politics emphasize oral Inuktitut uploads rather than syllabic texts," the About Us page declares. While the site focuses on Inuit concerns and materials, its creators have explicitly opened the platform to other indigenous users. "Unfortunately, most indigenous communities do not have sufficient Internet bandwidth access, to view and upload multimedia, at full quality and speed," the site observes, "The IsumaTV Mediaplayer is designed to allow remote communities to participate equally in a world driven by media, in their own language and in the immediacy of our times." ${ }_{34}$

Signs of emergence, those holes in the ground were a technology of preservation for both insects and Native Americans in early colonial North America - cultivated, deliberately maintained excavations. The bugs Bradford heard earned their Latin name, magicicada, from their seemingly supernatural ability to derive life from self-burial. "The emerging media of today," Sandra Gustafson has written, "can help us

Great Lakes Research Alliance for the Study of Aboriginal Arts and Cultures, https:// grasac.org/gks/gks_about.php. See also Tim Powell, 'Digitizing Cherokee Culture: Building Bridges between Libraries, Students, and the Reservation', MELUS 30.2 (2005), 79-98.

33 He Pātaka Kupu Ture / Legal Māori Archive, University of Wellington, http://www. nzetc.org/tm/scholarly/tei-corpus-legalMaori.html .

34 Isuma.TV, http://www.isuma.tv/en/about-us . 
to better understand and preserve the emerging media of early America, making visible the range of textual forms from wampum belts to staged readings." 35 In effect, Gustafson argues that we will be able to do history better, to see more with new technologies. No doubt this is true in part. But the pathway of questioning might go both ways in time. Bradford, Harriot, and Winslow offer us a sense of the disagreements about indigenous media archiving in the early colonial era; today's contests about networked archives, information design, and access often have both colonial origins and persistently colonialist objectives. But such disagreements are also opportunities to change the way archives function, both in the imagination and in the legal architectures of states, tribes, and other collectives. Even as we make knowledge of the newly widespread contents of databases of previously obscure or rare or ancient material, we must interrogate the very constitution and maintenance of those databases and their relationship to the colonial past and still-colonial present. We are passersby, becoming diggers of holes. ${ }^{36}$ American Antiquarian Society II5.2 (2005), 249.

36 "The text is delivered to the user," Hans Zeller has written, "not for permanent ownership, but rather as a task in which to participate." Zeller, "Record and Interpretation: Analysis and Documentation as Goal and Method of Editing', Contemporary German Editorial Theory, George Bornstein et al., eds. (Ann Arbor, MI: University of Michigan Press, 1995), 50. 
